Article

\title{
Evolution Characteristics of Separated Vortices and Near-Wall Flow in a Centrifugal Impeller in an Off-Designed Condition
}

\author{
Shihao Zhou, Peifeng Lin $(\mathbb{D}$, Wei Zhang $* \mathbb{(}$ and Zuchao Zhu \\ National-Provincial Joint Engineering Laboratory for Fluid Transmission System \\ Technology, Zhejiang Sci-Tech University, Hangzhou 310018, China; shihaochou@yeah.net (S.Z.); \\ linpf@zstu.edu.cn (P.L.); zhuzuchao@zstu.edu.cn (Z.Z.) \\ * Correspondence: zhangwei@zstu.edu.cn
}

Received: 8 October 2020; Accepted: 16 November 2020; Published: 19 November 2020

\begin{abstract}
Flow separation is undesirable and lowers the efficiency of centrifugal impellers. In this study, the evolution characteristics of separated vortices in a centrifugal impeller are studied under the off-designed flow rate condition. Unsteady Reynolds-Averaged Navier-Stokes (URANS) with standard $k-\varepsilon$ turbulent model is applied to simulate the alternating stall in the six-blade centrifugal impeller. We present and analyze the distributions of pressure gradient (either adverse or favorable) and skin friction coefficients on both sides of the blade for the stalled and unstalled passages to study the relationship between pressure gradient and separation of boundary layer flow. The evolution of skin friction coefficient is also presented at various axial cross sections. Numerical results reveal that, for the stalled passage, the increase in adverse pressure gradient on the pressure surface near the middle of the blade $\left(S / S_{0}=0.4\right)$ is much larger than that of the suction surface during a vortex formation cycle. The skin friction coefficient on the pressure surface also increases in magnitude sharply and the variation shows a peak-valley trend, while the coefficient on the suction surface increases slowly. Comparing the distribution of skin friction coefficient on the pressure surface of the same blade at different axial cross sections, it is found that the skin friction coefficient notably increases at $\mathrm{S} / \mathrm{S}_{0}=0.6$ on the middle axial cross section $\left(\mathrm{Z} / \mathrm{b}_{2}=0.5\right)$. For the unstalled passage, both the pressure and suction surfaces produce favorable pressure gradients. The skin friction coefficient on the pressure surface shows an increasing trend around $S / S_{0}=0.5$, and a large vortex can be seen at the exit of the impeller. The variation of skin friction coefficient on the suction surface is relatively mild; thus, the flow is relatively stable. It is clarified that the effect of adverse pressure gradient and wall shear stress jointly cause separation of the boundary layer; thus, the separated vortices are generated in the rotating impeller and deteriorate the performance of the impeller.
\end{abstract}

Keywords: stall; separated vortices; boundary layer separation; pressure gradient; skin friction coefficient

\section{Introduction}

Separated flow is a complex phenomenon in fluid mechanics. It is widely encountered in flow around various geometries such as bluff cylinders and hydrofoils and in turbo-machineries [1]. As the impeller runs under off-design conditions, due to the nonzero angle of attack of flow with respect to the blades, separated vortices may be generated in the impeller. The continuous generation and shedding of vortices often induce low-frequency pressure pulsation, which increases noise and intensifies vibrations, resulting in deteriorated performance or even accidents [2]. The vortices in the impeller are normally unstable because of the shear stress which finally viscously diffuses the vortices, and new vortices still form. From an energy point of view, these downstream moving vortices take away a 
majority part of energy, which is equivalent to an additional drag acting on the surrounding flow; this will lower the dynamic efficiency of the turbo-machineries.

In order to understand the complex separation mechanisms for flow in a centrifugal impeller, a number of works have been conducted either by numerical simulations or experiments. Andreas and Gunther [3] performed a large-eddy simulation based on the second-order cumulative rate method combined with the eddy current viscosity sub-grid scalemodel and pointed out that flow instability such as a rotating stall can lead to severe vibrations in turbo-machines if the eigenfrequency of the impeller equals the stall frequency. Byskov et al. [4] conducted a detailed experimental measurement on flow in a shrouded centrifugal impeller and reported a two-passage phenomenon (stalled and unstalled passages) for flow rate $Q=0.25 Q_{d}$, which was not previously reported. Tan et al. [5] studied the unsteady cavitation flow of centrifugal pumps operating under off-design conditions by using the improved cavitation mode. The authors found that, under partial discharge, the pressure fluctuation of the cavitation flow is higher than that of the non-cavitation flow. Olivier and Hakan [6] used OpenFOAM to carry out steady and unsteady numerical simulations of a centrifugal pump with vane diffusers to study the rotor-stator interaction. They found that the steady simulation produces results which are in reasonable agreement with the experimental data. Huang et al. [7] used a third-order SGS model to simulate the stall phenomenon in the impeller of a centrifugal pump under quarter-load condition. Further study of the two components of the production and the rotation shows that they jointly transport certain energy from the Reynolds component $R_{v v}$ to $R_{u u}$. Ren et al. [8] used the SST $k$ - $\omega$ turbulence model to study flow in a centrifugal pump under four different flow rates $\left(1.0 Q_{d}, 0.7 Q_{d}\right.$, $0.5 Q_{d}$, and $0.3 Q_{d}$, where $Q_{d}$ is the designed flow rate). The results show that, as the flow rate decreases, the stall can be categorized as preliminary stall and stationary stall. As the flow rate decreases from $1.0 Q_{d}$ to $0.3 Q_{d}$, the inlet angle of the impeller increases from 35 degrees to 70 degrees, which is the direct cause of the stationary stall. Akiha et al. [9] analyzed the performance of the first stage of a multi-stage pump through experimental and numerical data and concluded that the reason for the positive slope characteristic in the low flow rate region is the increased loss in the diffuser. In addition, the vortex on the trailing edge of the diffuser blades will block airflow and cause a separate airflow on the leading edge, resulting in a rotation stall. Manish et al. [10] used particle image velocimetry (PIV) and pressure fluctuation measurement to study the generation and development of stall in a centrifugal pump with a vaned diffuser. It is found that, as the flow velocity decreases, the size of the leakage and reversed flow in the stalled diffuser passage increases and the size of the stall unit diffuses from one diffuser passage to two diffuser passages. Akin and Rokwell [11] used PIV to study the wake of a model impeller in a rotating machine and its interaction with fixed diffuser blades. They used instantaneous streamline patterns and vortex contours to describe flow separation. The observed phenomena are further elaborated through numerical simulation.

The unstable flow phenomena such as rotating stall and surge are also studied for centrifugal compressors with air as the working fluid [12]. Due to the different working fluid and mechanics, the developmental mechanism of stall is studied accordingly for a compressor with a vaneless or vaned diffuser [13-15]. Some other types of pumps such as radial flow pumps, radial diffusion pumps, and mixed flow pumps working at low flow rate conditions would produce unstable vortices due to flow instability as the flow experiences deceleration in a diverging section [16-20]. Zhang et al. [21] numerically and experimentally investigated the stall inception mechanisms in a centrifugal compressor with volute. The results indicate that the stall inception onset is determined by the impeller leading edge (LE) spillage flow, and the occurrence time of trailing edge (TE) back flow is prior to the LE spillage. The nonuniform static pressure circumferential distribution at the impeller outlet induced by the volute tongue caused two stall inception regions located at certain circumferential positions, which are $120 \mathrm{deg}$ and 300deg circumferential positions at impeller LE, corresponding to the circumferential static pressure peak (PP) and bulge regions at impeller outlet, respectively. Ceyrowsky et al. [22-24] mainly investigated one large external volute configured for different diffuser ratios and blade exit angles and coupled with different impellers by means of CFD to understand the relationship between volute matching and pressure distortion. It was found that pressure distortion is directly related to the 
volute's pressure recovery coefficient, and how the resulting pressure distortion evolves towards the impeller was analyzed.

The physics of unsteady flow in the impeller and volute of centrifugal turbo-machineries have been extensively studied, as reviewed above. The flow characteristics, such as the evolution of vortices and turbulent statistics, were presented and analyzed to reveal their influences on the performance of the impeller. We understand that the flow in a rotating centrifugal impeller experiences the effect of pressure gradient on the surface of the blade passage, which is essential in triggering the initial separation and the confinement from walls which strongly induce the three-dimensional patterns of the flow; thus, the three-dimensional patterns of the flow have to be revealed, which may help in the redesign of the impeller and may improve the performance of the whole machine. In this paper, we performed a numerical simulation investigation on the internal flow in a shrouded centrifugal impeller under the off-designed flow rate condition. The motivation is to explore the three-dimensional characteristics of the flow in the impeller as presented and analyzed by the distributions of the pressure coefficient and skin friction coefficient on both the pressure and suction surfaces in the stalled and unstalled passages, which reveal the characteristics of near-wall flow behaviors. The formation and evolution of the separated vortices are discussed on various cross sections in the axial direction.

The paper is organized as follows. Section 2 gives the physical model of the impeller, the details of the numerical simulation, and the validation and grid independence study. Section 3 presents and discusses the flow characteristics. Some conclusions are given in Section 4.

\section{Numerical Setup}

\subsection{Physical Model}

The centrifugal impeller investigated in our work is the first stage of a two-stage centrifugal pump that has been numerically and experimentally studied by Byskov et al. [4]. The geometry of the centrifugal impeller investigated in our study is shown in Figure 1, and the key specifications are listed in Table 1. The impeller has six blades, and the specific speed is 26.3; the diameter of the inflow section is $71 \mathrm{~mm}$ and is $190 \mathrm{~mm}$ for the outflow section. To model the inflow and outflow at the working condition of the impeller, we applied two extended sections upstream and downstream of the impeller, respectively, where constant and uniform boundary conditions can be applied for the flow quantities, as shown in Figure 2. The outflow section extends for about 30\% of the outlet diameter of the impeller to ensure no reversed flow appears at the outflow boundary.

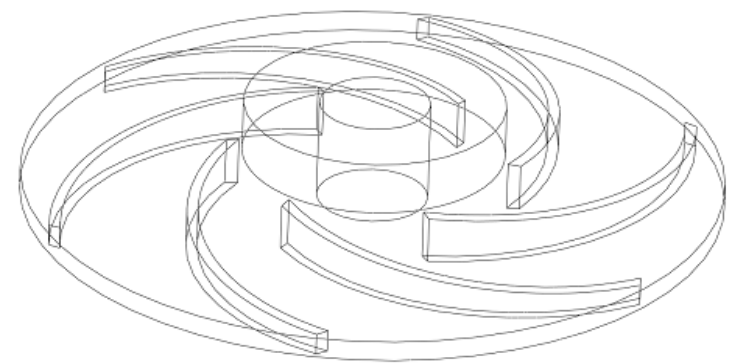

Figure 1. Configuration of the six-blade impeller.

Table 1. Geometric specifications of the centrifugal impeller.

\begin{tabular}{cc}
\hline Parameter & Value \\
\hline Inlet Diameter $D_{1}$ & $71.0 \mathrm{~mm}$ \\
Outlet Diameter $D_{2}$ & $190.0 \mathrm{~mm}$ \\
Inlet Height $b_{1}$ & $13.8 \mathrm{~mm}$ \\
Outlet Height $b_{2}$ & $5.8 \mathrm{~mm}$ \\
Number of Blades $Z$ & 6 \\
Blade Thickness $t$ & $3.0 \mathrm{~mm}$ \\
Inlet Blade Angle $\beta_{1}$ & $19.7^{\circ}$ \\
Outlet Blade Angle $\beta_{2}$ & $18.4^{\circ}$ \\
Blade Curvature Radius $R_{b}$ & $70.0 \mathrm{~mm}$ \\
Specific Speed $N_{s}$ & 26.3 \\
\hline
\end{tabular}




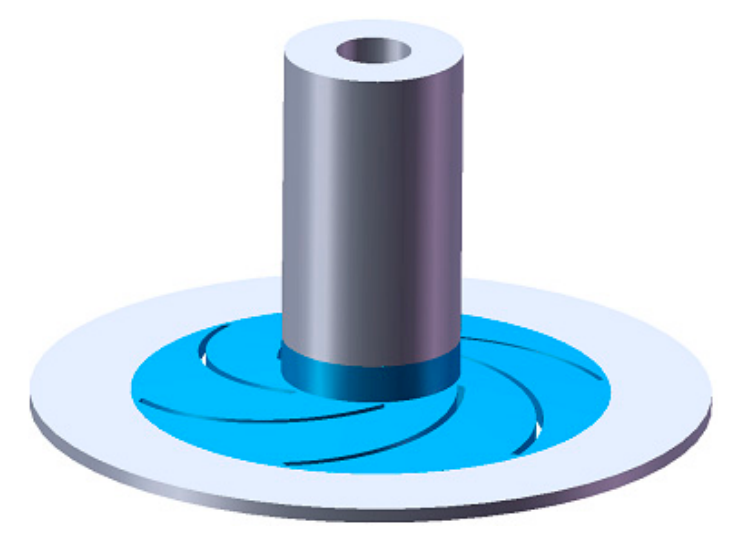

Figure 2. Geometry of the computation domain.

\subsection{Mesh Generation}

The reliability of the simulation and accuracy of the numerical results rely on the quality of the mesh. In our work, we used a multi-block structured mesh for the whole computational domain, including the impeller and the extended inflow and outflow sections. Figure 3 shows an enlarged view of the structured mesh around the blade. It is seen that the orthogonal mesh is produced on the surfaces of the blade as well as the leading and trailing edges. The minimum orthogonal quality is 0.43 , and the maximum orthogonal skewness is 0.57 ; the maximum aspect ratio is 0.59 . The mesh has undergone sufficient quality inspection to meet the computational requirements.

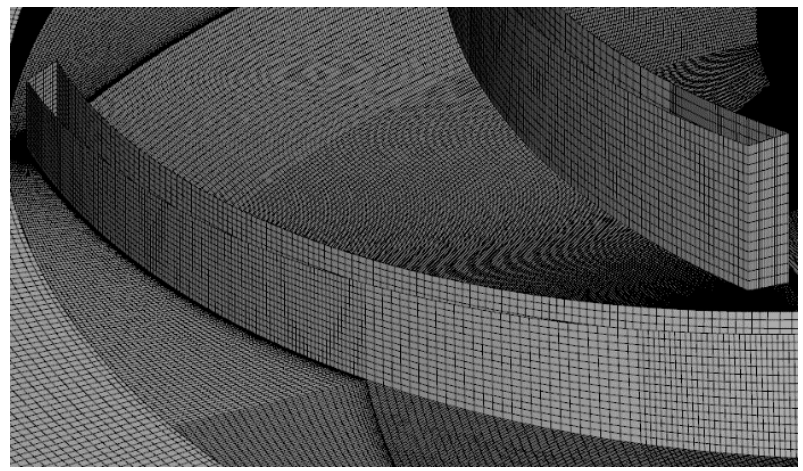

Figure 3. Enlarged view of the structured mesh.

\subsection{Numerical Methods}

The incompressible flow of the impeller is governed by equations of conservation of mass and momentum:

$$
\begin{gathered}
\frac{\partial u_{i}}{\partial x_{i}}=0 \\
\frac{\partial u_{i}}{\partial t}+u_{j} \frac{\partial u_{i}}{\partial x_{j}}=f_{i}-\frac{1}{\rho} \frac{\partial P^{*}}{\partial x_{i}}+v \frac{\partial^{2} u_{i}}{\partial x_{j} \partial x_{j}}
\end{gathered}
$$

where $x_{i}$ is the direction component of the Cartesian coordinate system; $u_{i}$ is the velocity component; $P^{*}$ is the pressure considering the conversion of turbulent kinetic energy and centrifugal force; $f_{i}$ is the component of the volume force including the centrifugal force and Coriolis force; and $v$ is the kinematic viscosity coefficient.

The standard $k-\varepsilon$ turbulence model is employed to simulate the turbulent flow in the centrifugal impeller. The transport equations of the turbulent kinetic energy $k$ and turbulent dissipation rate $\varepsilon$ are as follows: 


$$
\begin{gathered}
\frac{\partial k}{\partial t}+\frac{\partial}{\partial x_{i}}\left(k u_{i}\right)=\frac{1}{\rho} \frac{\partial}{\partial x_{j}}\left[\left(\mu+\frac{\mu_{t}}{\sigma_{k}}\right) \frac{\partial k}{\partial x_{j}}\right]+G_{k}+G_{b}-\rho \varepsilon-Y_{M}+S_{k} \\
\frac{\partial \varepsilon}{\partial t}+\frac{\partial}{\partial x_{i}}\left(\varepsilon u_{i}\right)=\frac{1}{\rho} \frac{\partial}{\partial x_{j}}\left[\left(\mu+\frac{\mu_{t}}{\sigma_{\varepsilon}}\right) \frac{\partial \varepsilon}{\partial x_{j}}\right]+C_{1 \varepsilon} \frac{\varepsilon}{k}\left(G_{k}+C_{3 \varepsilon} G_{b}\right)-C_{2 \varepsilon} \rho \frac{\varepsilon^{2}}{k}+S_{\varepsilon}
\end{gathered}
$$

in which $G_{k}$ represents the turbulent kinetic energy term caused by the laminar velocity gradient; $G_{b}$ is the turbulent kinetic energy term produced by buoyancy; $Y_{M}$ represents the contribution term of the turbulent pulsation expansion in the compressible flow to the global flow to the dissipation rate; $C_{1}, C_{2}$, and $C_{3}$ are constants; $\sigma_{k}$ and $\sigma_{\varepsilon}$ and are the turbulent Prandtl numbers of the $k$-equation and $\varepsilon$-equation; and $S_{k}$ and $S_{\varepsilon}$ are user-defined turbulent kinetic energy terms and turbulent dissipation source terms. According to the recommended values [25], the values of $C_{1 \varepsilon}, C_{2 \varepsilon}, C_{\mu}, \sigma_{k}$, and $\sigma_{\varepsilon}$ are fixed at 1.44, 1.92, 0.09, 1.0, and 1.3, respectively. Since the flow is incompressible, the source terms $G_{b}$, $Y_{M}, S_{k}$, and $S_{\varepsilon}$ are set as zero.

The centrifugal impeller works at an off-designed flow rate $Q=0.76 \mathrm{~L} / \mathrm{s}$, which is set as the mass flow rate condition at the inflow boundary. The zero-gauge pressure condition is set at the outflow boundary. The no-slip condition is set for velocity on all solid walls.

The numerical simulation was performed using ANSYS-Fluent 16.0. The governing equations are discretized in space by second-order central difference scheme and discretized in time by a second-order implicit scheme. The velocity and pressure decoupling use the SIMPLEC algorithm. The convergence residual is set to $10^{-4}$, and the maximum iteration is 15 times in each time step. In order to lower computational time and resource request, a steady-state simulation was first carried out using the same boundary conditions and computational parameters, and the converged results with residual smaller than $10^{-4}$ were used to initialize the unsteady simulation. In the unsteady simulation, 360 physical time steps were set as the impeller rotates for one revolution; thus, the physical time step size is $2.3 \times 10^{-4}$ seconds. We first run the unsteady simulation for 1.656 seconds, corresponding to 20 revolutions of the impeller, and then continue for one more revolution, which produces data for the following analysis and discussion.

\subsection{Mesh Independence Study and Validation}

In this study, the multi-block structured mesh is refined on all solid walls and boundaries to provide better resolution on local flow with large velocity gradient, as shown in Figure 3. The mesh refinement guarantees that the value of $y^{+}$on the surfaces of blade, hub, and shroud is normally $y^{+}<10$ in most regions, while near the outlet of the impeller, the value could increase to about 15 . To assess the influence of the mesh number on the accuracy of the results, four different meshes are tested and the pumping head of the impeller is given in Table 2. It can be seen from Table 2 that the difference of the pumping head between Mesh 2 and Mesh 1 is $0.09 \mathrm{~m}$ and that the difference between the Mesh 4 and Mesh 3 is $0.07 \mathrm{~m}$. Considering the balance of numerical accuracy and computational cost, we believe the configuration of 7.6 million meshes is sufficient for the present simulation, especially for the near-wall flow.

Table 2. Mesh independence study.

\begin{tabular}{ccc}
\hline & Mesh Number & $\mathbf{H} / \mathbf{m}$ \\
\hline Mesh 1 & $4,740,324$ & 2.42 \\
Mesh 2 & $5,598,924$ & 2.51 \\
Mesh 3 & $7,642,362$ & 2.31 \\
Mesh 4 & $9,185,268$ & 2.38 \\
\hline
\end{tabular}

\section{Results and Discussion}

\subsection{General Description of the Evolution of Vortices}

The experimental results of Byskov et al. [4] concluded that, for the centrifugal impeller operating under a quarter flow rate $Q / Q_{n}=0.25$, the flow is unstable and stall cells emerge in the passages. 
The distribution of streamlines in the impeller at successive moments is given in Figure 4 at the half-span cross section $Z / b_{2}=0.50$. The notable two-passage phenomenon is observed in that the passages are stalled and unstalled in an alternative way, as denoted in the figure, where passages I, III, and V are stalled where severe flow separation and multiple stall cells are observed and where passages II, IV, and VI are unstalled where only small separated vortices occasionally emerge.

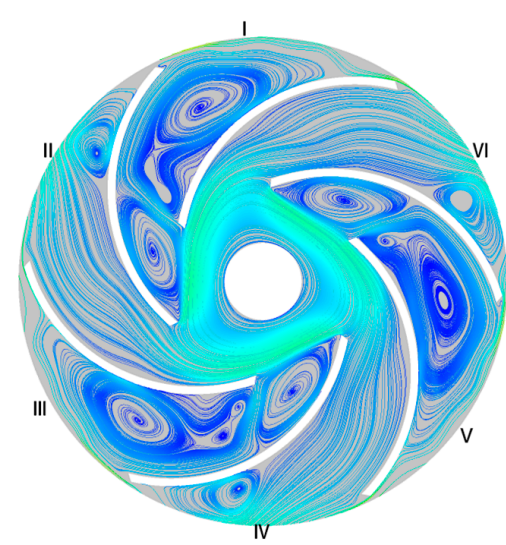

(a) $t=1 / 12 T$

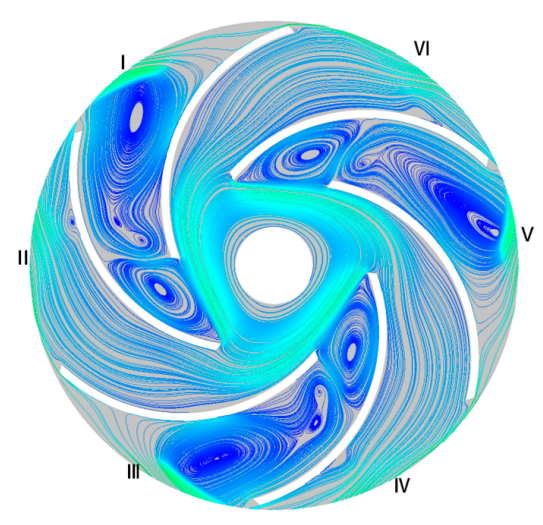

(b) $t=3 / 12 \mathrm{~T}$

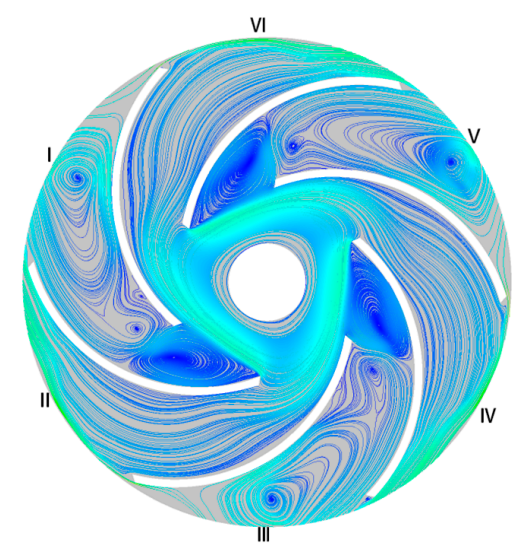

(c) $t=5 / 12 T$

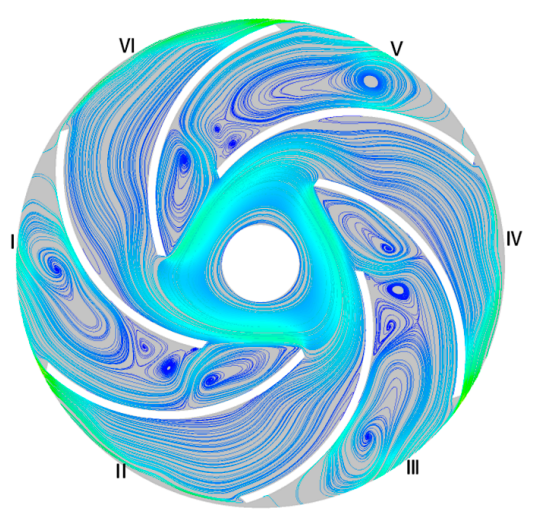

(d) $t=7 / 12 T$

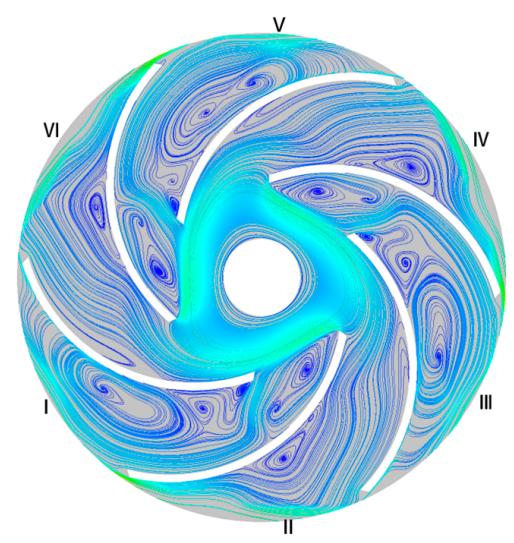

(e) $t=9 / 12 T$

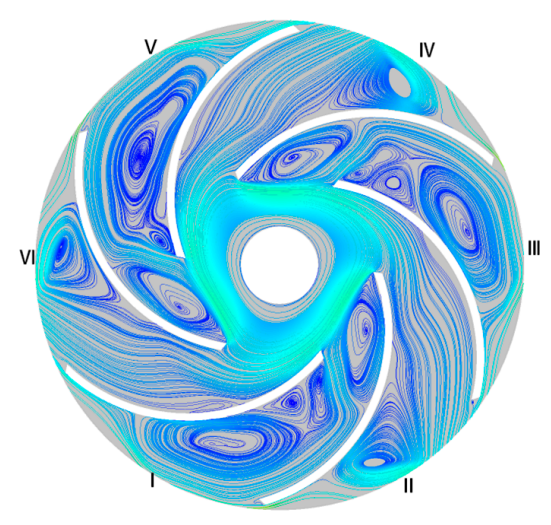

(f) $t=11 / 12 T$

Figure 4. Evolution of streamlines with the rotation of the impeller at different moments within one cycle: the streamlines are colored by the velocity magnitude.

For the stalled passage I, a large vortex appears on the suction surface of the leading edge of the blade, which blocks the upstream inflow, and its position hardly changes with the rotation of the impeller. The formation of this stall cell reduces the flow rate in this passage and consequently 
induces an even larger stall cell on the pressure surface of the blade in the downstream part of the passage; the downstream stall cell sheds with the rotation of the impeller and moves in the downstream direction. For the unstalled passage II, a separated vortex is generated on the pressure surface of the blade near the outlet of the impeller. This vortex evolves in size with the rotating impeller but not the position and may vanish during part of the cycle; it almost does not affect the main flow in the passage. The evolution process of the separated vortices of different scales in other passages is quite similar to those reported in passages I and II.

\subsection{Boundary Layer Flow in the Stalled Passage}

In this section, we analyze and discuss the flow in the stalled passage I to demonstrate the evolution of the vortices. Since the near-wall flow is significant in determining the hydrodynamic performances of the impeller and even the pump, the characteristics of the flow are presented by the distributions of pressure coefficient and skin friction coefficient on the surfaces of the blade at various axial cross sections. The dimensionless pressure coefficient is defined as follows:

$$
C_{P}(\mathbf{x}, t)=\frac{p(\mathbf{x}, t)-p_{2}}{0.5 \rho U_{1}^{2}}
$$

where $p$ is the instantaneous static pressure at the blade surface; $p_{2}$ is the static pressure at the outlet of the impeller; and $U_{1}$ is the averaged inflow velocity. The skin friction coefficient is defined as follows:

$$
C_{f}(\mathbf{x}, t)=\frac{\tau_{w}(\mathbf{x}, t)}{0.5 \rho U_{1}^{2}}
$$

where $\tau_{w}$ is the local wall shear stress.

The stalled passage I consists of the pressure surface of one blade (denoted as ps1) and suction surface of the other blade (denoted as ss1). In order to clarify the evolution of the separated vortices in a cycle, here, we present the instantaneous values of the quantities at six moments which are the same as in Figure 4, i.e., 1/12T, 3/12T, 5/12T, 7/12T, 9/12T, and 11/12T, that the impeller rotates for 20 degrees between two successive moments.

Figure 5 gives the distribution of pressure coefficient on both surfaces of the blade for the cross section at the axial position $Z / b_{2}=0.15$, which is close to the hub of the impeller. The local coordinate $S$ along the curved surface is chosen as the abscissa and is normalized by the arc length $S_{0}$ of respective surface; thus, $S / S_{0}=0.0$ and 1.0 represent the leading and trailing edges, respectively. For the pressure surface shown in Figure $5 \mathrm{a}$, the pressure of the fluid experiences an increase for the majority of the surface and is the most notable for the region $S / S_{0}=0.5-0.8$, representing an adverse pressure gradient $\partial p / \partial s>0$ (APG). Since the APG on the blade surface is generally aligned in the direction with of boundary layer flow, the flow is decelerated under the combined effect of the AFG and the viscous force and consequently separates from the blade surface. The separated boundary layer flow is lifted up away from the pressure surface and becomes part of the main flow in the passage; thus, a large-scale vortex is generated on the pressure surface, which occupies almost the entire passage, as shown in Figure 4 . The flow downstream of $S / S_{0}=0.6$, i.e., close to the outlet of the impeller, is accelerated by the favorable pressure gradient (FPG) roughly in the small region $S / S_{0}=0.8-1.0$. For the distribution of pressure coefficient on the suction surface shown in Figure $5 b$, it is different from that of the pressure surface in that the pressure coefficient almost monotonically increases for the whole blade surface, resulting in a strong APG in the region $S / S_{0}=0.3-1.0$. The pressure coefficient varies slightly for the inlet region of the impeller but is more pronounced close to the outlet of the impeller where the local flow is alternatively occupied by the large-scale separated vortex and reattached flow. 


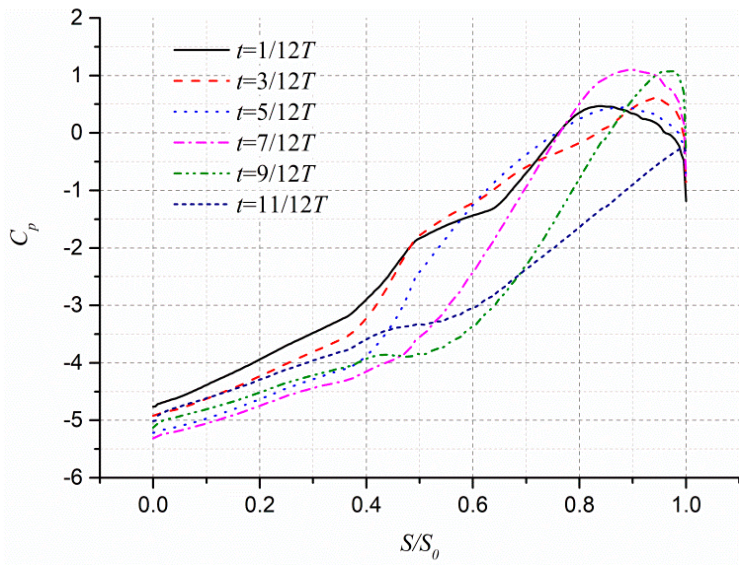

(a)

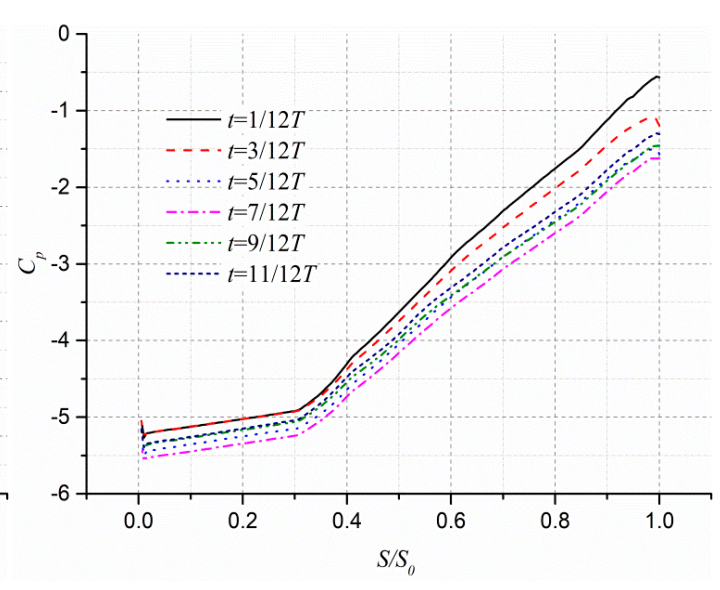

(b)

Figure 5. Distribution of pressure coefficient on the blade surface for the $Z / b_{2}=0.15$ cross section:

(a) pressure surface and (b) suction surface.

As the boundary layer flow is separated from the blade surface, the fluid is injected into the external main flow, which may then reattach to the blade surface in the downstream region. The wall shear stress, as quantitatively represented by the skin friction coefficient, is a reflection of the magnitude of velocity of boundary layer flow on the blade surface and is affected by the local pressure gradient. Here, we analyze the distribution and evolution of the skin friction coefficient to demonstrate the intensity of the circulation of the separated vortices in the passage. Figure 6 shows the distribution of the instantaneous skin friction coefficient on the blade surface at the axial cross section near the hub of the impeller $\left(Z / b_{2}=0.15\right)$. The curves are shown from the leading to trailing edges of the blade at several moments similar to that described above.

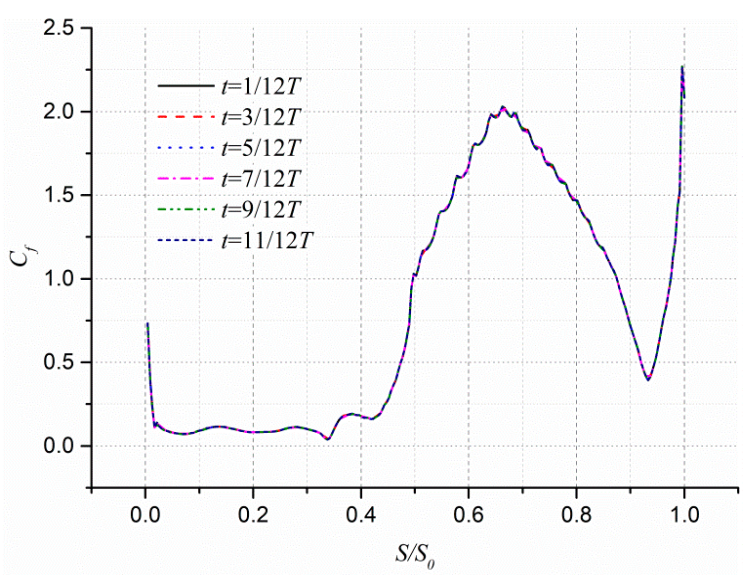

(a)

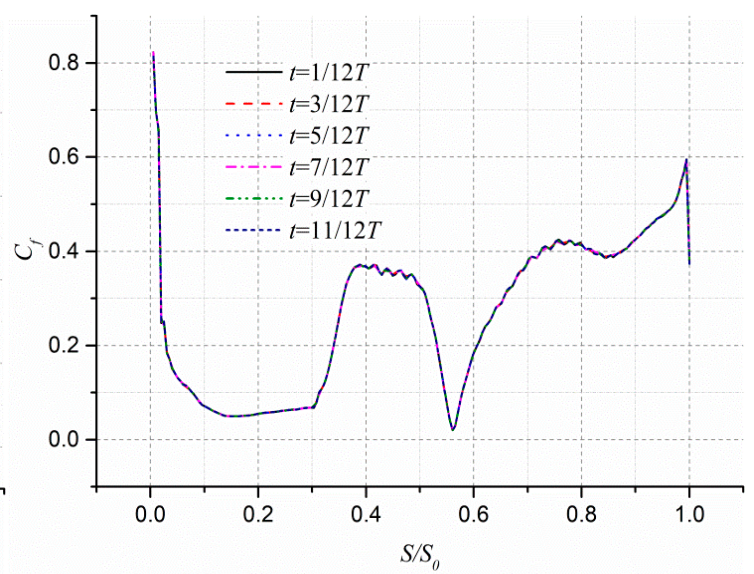

(b)

Figure 6. Distribution of skin friction coefficient on the blade surface for the $Z / b_{2}=0.15$ cross section:

(a) pressure surface and (b) suction surface.

It is seen from the figure, the variation amplitude of the skin friction coefficient is higher on the pressure surface and the magnitude is also generally higher. Consequently, we can anticipate that the velocity of the near-wall flow is higher on the pressure surface, which induces more energy loss. From the position of $S / S_{0}=0.5$, the curves start to increase sharply and to reach the local peak at around $S / S_{0}=0.7$. The increased wall-tangent velocity is mainly attributed to the acceleration from APG on the surface as the primary vortex circulates in the passage, as seen in Figure 4 . The magnitude of velocity then decreases until $S / S_{0}=0.95$ as the passage expands in the area in which the velocity generally decreases close to the outlet of the impeller, and the jump right at the trailing edge results 
from the local favorable pressure gradient (FPG) field, and the interaction of the passage flow and that outside of the passage, where the flow is not severely restricted by the blade surfaces and has a higher velocity. Different distribution patterns of the skin friction coefficient occur for the suction surface; more increasing or decreasing is observed. The local minimum at around $S / S_{0}=0.55$ corresponds to the junction of the two vortices on the suction surface in which the local flow approximately perpendicularly impinges on the surface. It is worth emphasizing here that, for the boundary layer flow of both pressure and suction surfaces, there is almost no temporal variation of the velocity for the whole surface, as reflected by the overlapping curves in both subfigures. This indicates that, although the structural evolution of the separated vortices is clearly seen in Figure 4, the boundary layer flow is hardly affected in terms of velocity magnitude during the rotation but is almost constant.

The analysis and discussions presented above demonstrate the characteristics of boundary layer flow of the blade under the constraint of the hub surface. To investigate the characteristics of flow in the central region of the passage, Figure 7 shows the distribution of the pressure coefficient on the pressure and suction surfaces of the blade on the cross section at axial position $Z / b_{2}=0.50$. It is seen in the figure that generally the distributions are quite similar to that on the $Z / b_{2}=0.15$ cross section. For the pressure surface at $t=1 / 12 T$, the pressure coefficient starts to increase rapidly from $S / S_{0}=0.4$; thus, the intensity of APG also increases accordingly. The magnitude of the pressure coefficient is then decreased as a whole. At $t=7 / 12 T$ and $t=9 / 12 T$, an even stronger APG field emerges in the region $S / S_{0}$ $=0.6-0.9$ and is almost the same as that on the $Z / b_{2}=0.15$ cross section. This indicates that the effect of the hub surface in constraining the flow is weak even in the region close to the hub in which the flow is quite similar to that in the central region of the passage; thus, the flow in the passage is quasi-2D and only small variation occurs along the axial direction, as also seen in Figure $7 \mathrm{~b}$ for the suction surface.

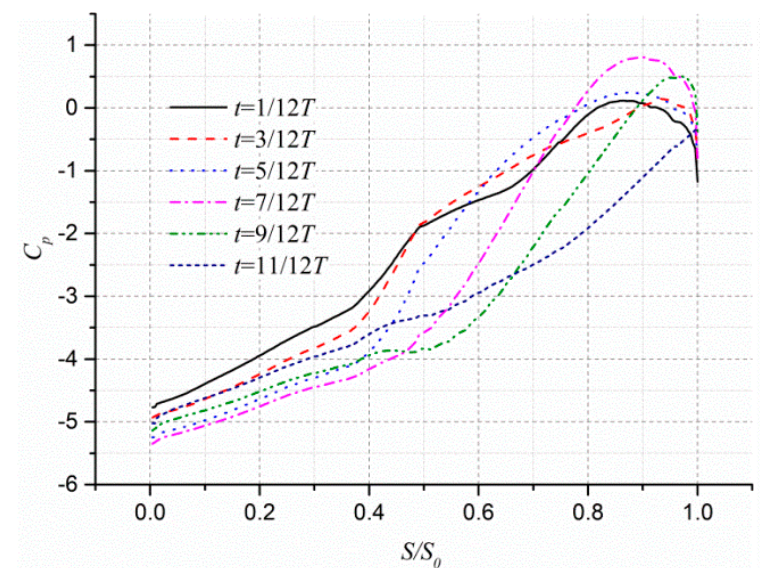

(a)

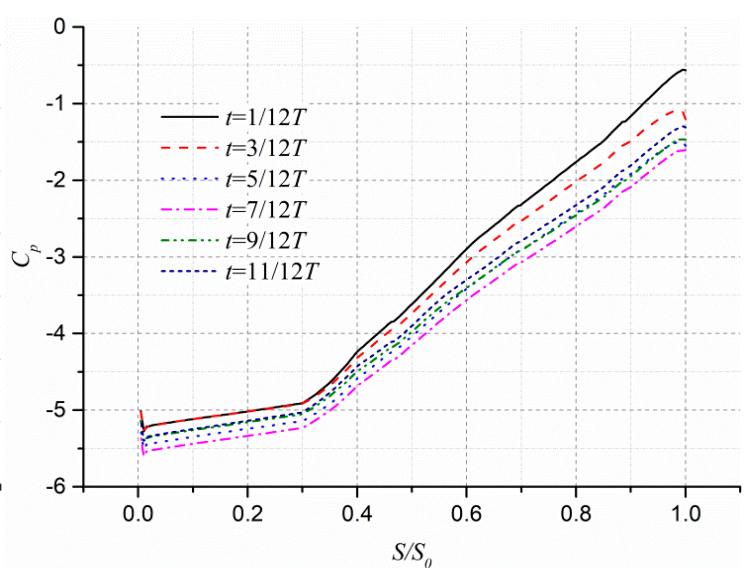

(b)

Figure 7. Distribution of the pressure coefficient on the blade surface for the $Z / b_{2}=0.5$ cross section: (a) pressure surface and (b) suction surface.

The boundary layer flow exhibits an entirely different distribution pattern on the pressure surface of the blade on the $Z / b_{2}=0.50$ cross section compared to the $Z / b_{2}=0.15$ cross section, as shown by the distribution of the skin friction coefficient in Figure 8. The skin friction coefficient keeps increasing roughly from $S / S_{0}=0.45$ until the trailing edge, and the decrease on the $Z / b_{2}=0.15$ cross section no longer appears here. This indicates a smaller vortex within the passage on the $Z / b_{2}=0.50$ cross section in which the flow is less blocked, and the flow moves in the radial direction towards the outlet of the impeller. The distribution of the skin friction coefficient on the suction surface is quite similar to that on the $Z / b_{2}=0.15$ cross section, meaning that the local flow patterns are almost identical. 


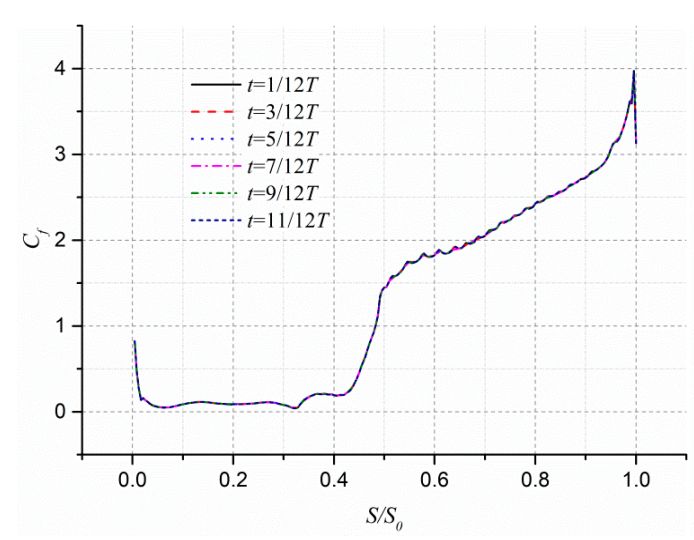

(a)

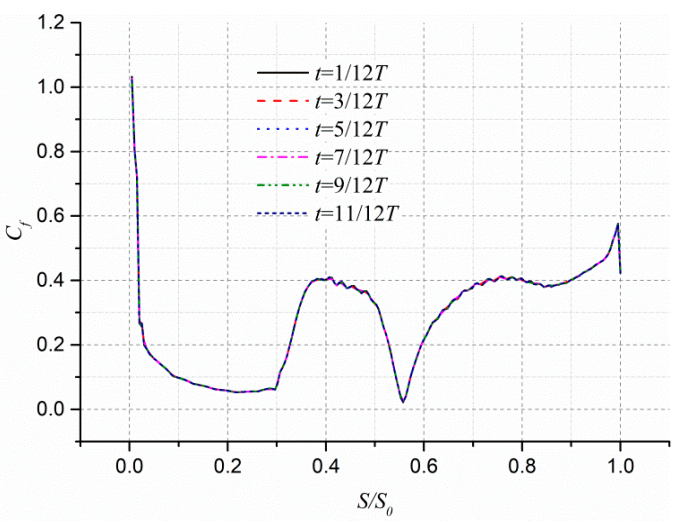

(b)

Figure 8. Distribution of the skin friction coefficient on the blade surface for the $Z / b_{2}=0.5$ cross section: (a) pressure surface and (b) suction surface.

In order to evaluate the effect of the hub and shroud surfaces on the internal flow of the impeller, Figure 9 gives the distribution of the skin friction coefficient on the pressure and suction surfaces of passage I on cross sections at various axial positions, i.e., from cross section close to the hub surface $\left(Z / b_{2}=0.15\right)$ to the shroud surface $\left(Z / b_{2}=0.84\right)$ with a distance between two neighboring cross sections of $1 \mathrm{~mm}$. Since we have already confirmed in Figures 6 and 8 that the skin friction coefficient almost does not vary in time, the difference among the curves in Figure 9 undoubtedly reflects the three-dimensionality of the flow, which is seldom considered in previous works in literatures. In general, the three-dimensionality of the flow is the most pronounced on the downstream half of the pressure surface roughly in the region $S / S_{0}=0.50-1.00$; the flow is generally decelerated close to the hub surface but accelerated in the central region of the passage. The curves also reveal that, due to the different geometries of the curved shroud and flat hub, the boundary layer flow is remarkably affected as revealed by the difference between the curves of $Z / b_{2}=0.15$ and $Z / b_{2}=0.84$, and of $Z / b_{2}=0.32$ and $Z / b_{2}=0.67$. The boundary layer flow moves at a relatively higher velocity on the cross section close to the shroud. For the first half of the pressure surface, the boundary layer flow is weakly or almost not affected by hub and shroud, and the flow is nearly two-dimensional for which no difference exists in the axial direction. The boundary layer flow on the suction surface of passage I is weakly three-dimensional from leading to trailing edge. The variation is small compared with the pressure surface; however, the flow becomes notably three-dimensional at around $S / S_{0}=0.05$, and the variation amplitude does not change until the trailing edge, reflecting the mild evolution of the boundary layer flow.

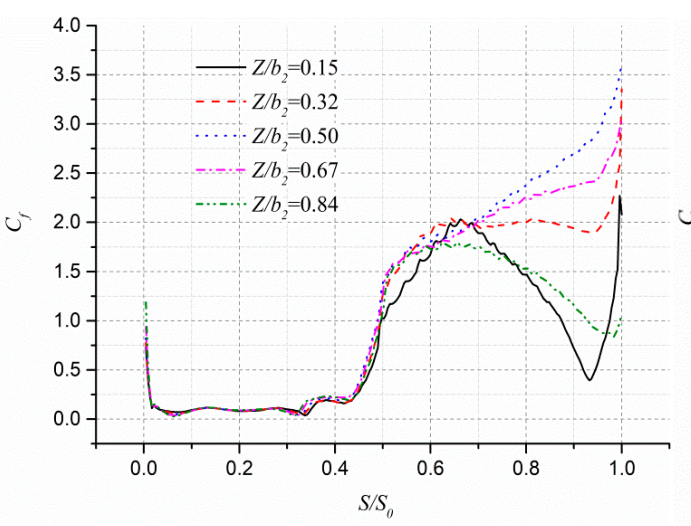

(a)

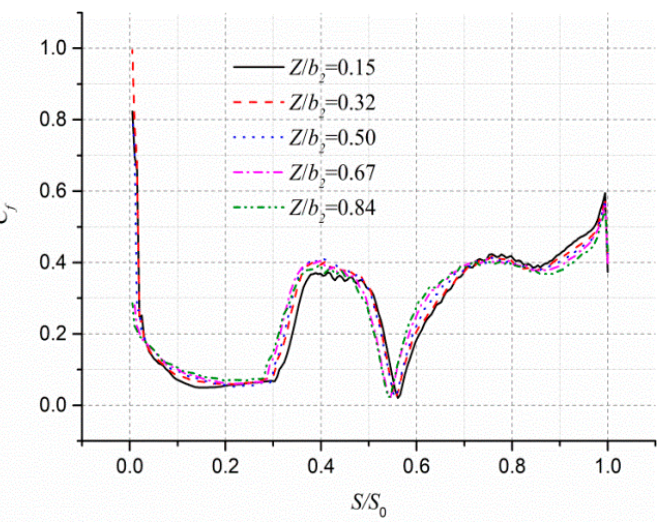

(b)

Figure 9. Comparison of the skin friction coefficient on the blade surface at different axial cross sections: (a) pressure surface and (b) suction surface. 


\subsection{Boundary Layer Flow in the Unstalled Passage}

As shown in Figure 4, the flow in the unstalled passages (passages II, IV, and VI) exhibit entirely different patterns compared with flow in the stalled passages. The flow moves through the passage without significant separation and formation of large-scale vortices. A small separated vortex is generated near the pressure surface during a portion of the vortex formation cycle which generally moves towards the outlet of the impeller with reduced size and intensity. Figure 10 gives the distribution of the pressure coefficient on both pressure and suction surfaces of the unstalled passage on the cross section at the axial position $Z / b_{2}=0.15$. As shown in Figure 10a, the pressure coefficient of the pressure surface in the region $S / S_{0}=0.50-0.80$ monotonically increases in time from $t=1 / 12 T$ to $t=9 / 12 T$. Under the adverse pressure gradient, the fluid in the boundary layer is subjected to higher pressure as it moves towards the outlet of the passage, while separation is not pronounced probably because of the relatively lower magnitude of adverse pressure gradient as compared with that of the stalled passage. The distribution of pressure coefficient on the suction surface is similar to that of the stalled passage.

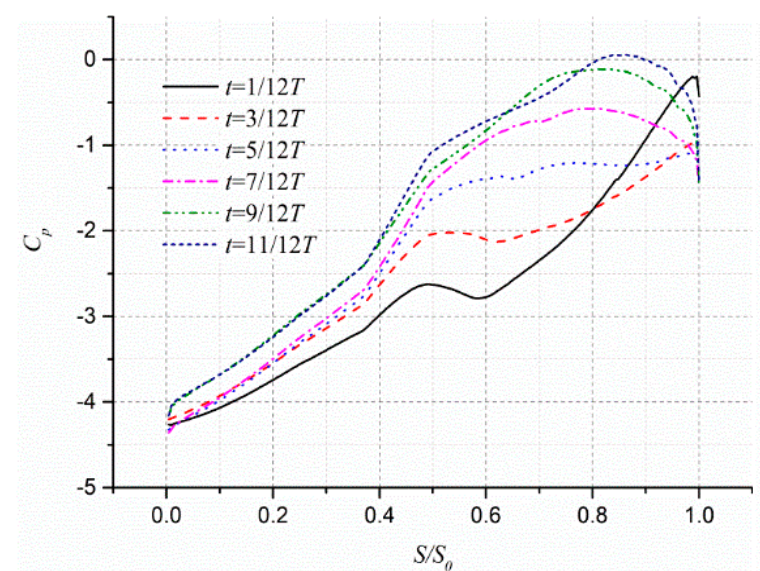

(a)

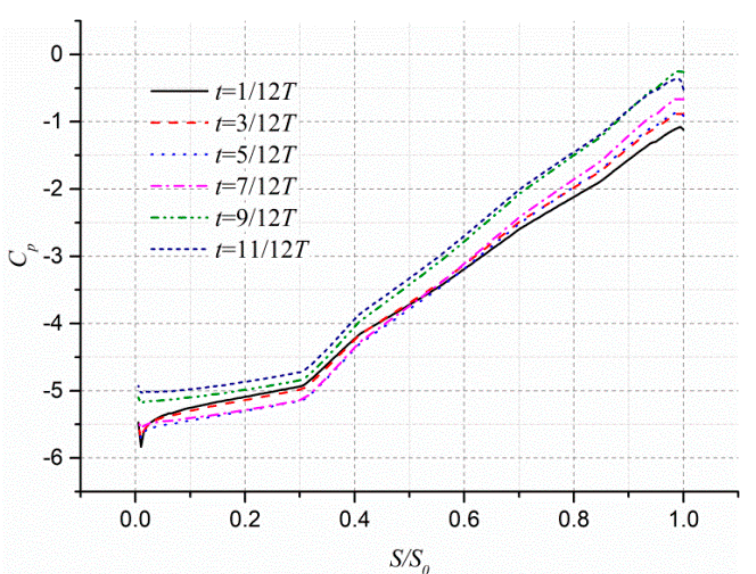

(b)

Figure 10. Distribution of the pressure coefficient on the blade surface for the $Z / b_{2}=0.15$ cross section: (a) pressure surface and (b) suction surface.

Figure 11 shows the distribution of skin friction coefficient on the pressure and suction surfaces of the unstalled passage on the cross-section at the axial position $Z / b_{2}=0.15$. It is seen in the figure that the skin friction coefficients of both the pressure and suction surfaces remain basically unchanged during a vortex formation cycle. On the pressure surface, the coefficient keeps almost monotonically increasing from the leading to trailing edge of the surface without significant local variation due to the separated vortex as that in the stall passage. For the suction surface, however, the wall-tangent velocity of the boundary layer flow remarkably decreases as the flow moves towards the outlet of the impeller, and no obvious fluctuation is observed, reflecting the decreased kinetic energy of the flow as a result of the viscous drag from the wall and the adverse pressure gradient. 


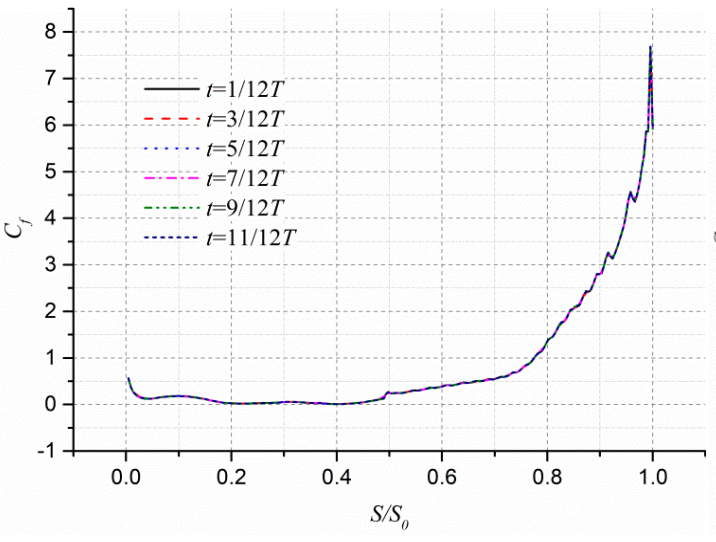

(a)

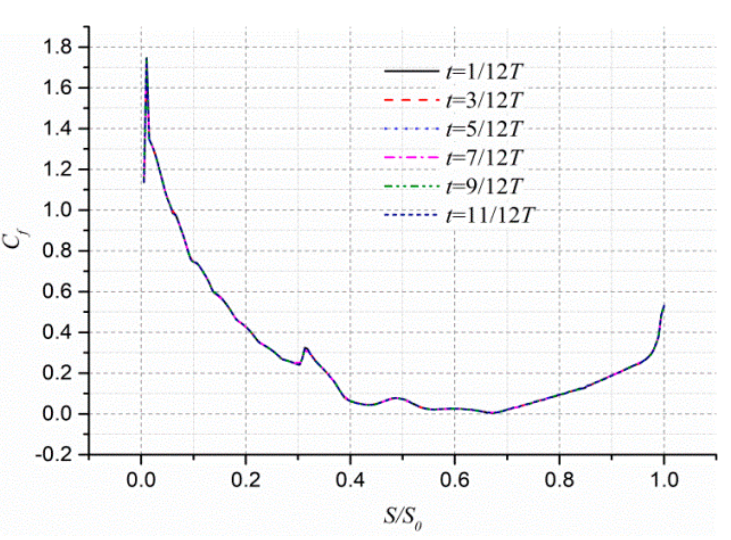

(b)

Figure 11. Distribution of the skin friction coefficient on the blade surface for the $Z / b_{2}=0.15$ cross section: (a) pressure surface and (b) suction surface.

We further explore the characteristics of boundary layer flow in the central region of the unstalled passage on the cross section at axial position $Z / b_{2}=0.50$. The distribution of pressure coefficient along the pressure and suction surfaces of the passage is given in Figure 12. During a vortex evolution cycle, the pressure coefficient of the pressure surface continues to increase, ranging from -4 to around 0 . In the region $S / S_{0}=0.6-1.0$, the magnitude of the APG of the pressure surface decreases slightly in time. As the flow is decelerated by APG, the flow will be reversed, and the size of the separated vortex will increase to some extent and moves to the outlet of the impeller. Meanwhile, the separation of boundary layer flow on the middle section of the passage is inevitably affected by the neighboring fluid. The distribution of skin friction coefficient on the blade surfaces is quite similar to that on the cross section near the hub, as shown in Figure 13. In the region $S / S_{0}=0.6-1.0$, the skin friction coefficient of the pressure surface begins to increase significantly and, then, the velocity gradient of the boundary layer increases; the greater the shear stress, the greater the energy loss. The velocity gradient of the boundary layer on the suction surface is continuously reduced except for the region at the trailing edge of the blade where the boundary layer flow is notably affected by the outflow from other passages.

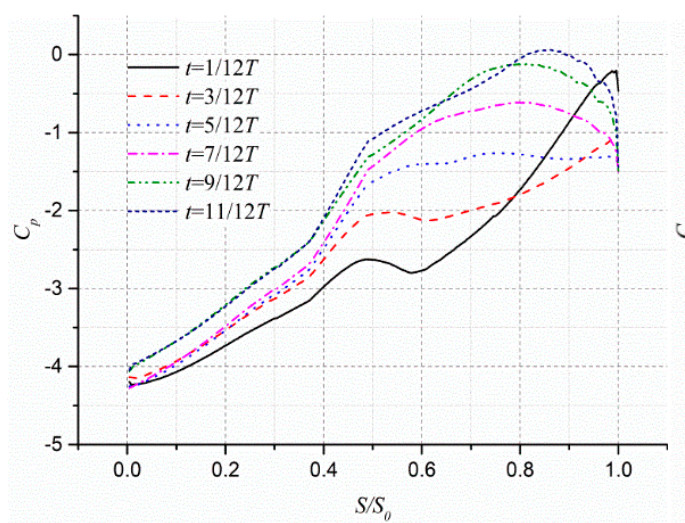

(a)

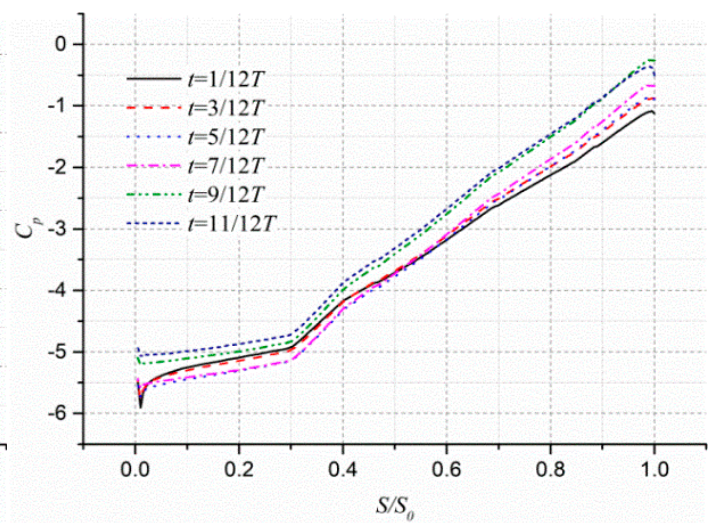

(b)

Figure 12. Distribution of the pressure coefficient on the blade surface for the $Z / b_{2}=0.5$ cross section: (a) pressure surface and (b) suction surface. 


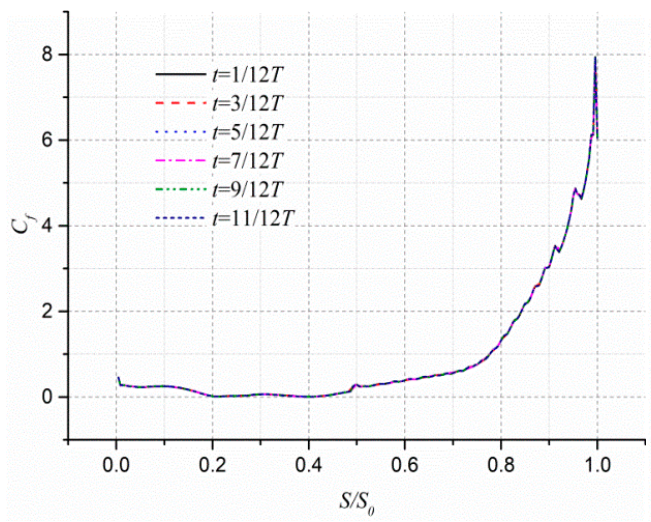

(a)

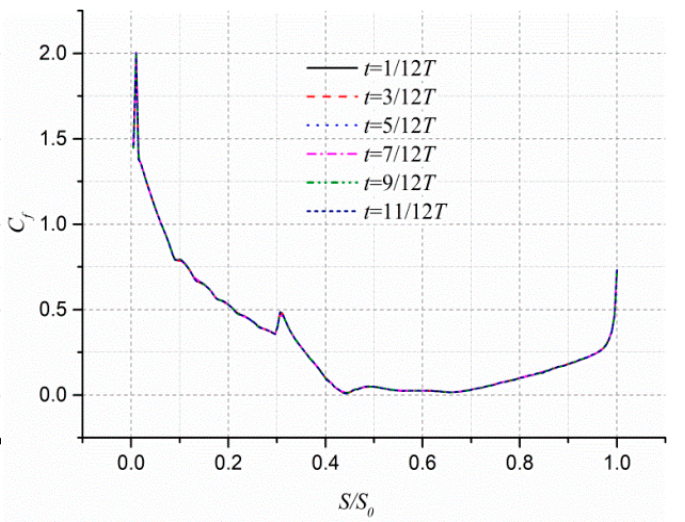

(b)

Figure 13. Distribution of the skin friction coefficient on the blade surface for the $Z / b_{2}=0.5$ cross section: (a) pressure surface and (b) suction surface.

It is found that the boundary layer flow in the unstalled passage is relatively weakly affected by the shroud and hub surfaces for which the pressure coefficient and skin friction coefficient exhibit quite consistent distributions on cross sections at different axial positions. The wall shear stress generated by the pressure surface is much greater than that of the suction surface, resulting in higher energy loss on the pressure surface. The distribution of streamlines in Figure 4 shows that the separated vortex on the pressure surface grows and decays periodically. However, there is no obvious formation of separated vortex on the suction surface.

The three-dimensionality of the flow in the unstalled passage is represented in Figure 14 by the profiles of skin friction coefficient on different axial cross sections. Since the distribution remains basically unchanged in time, this figure gives a direct reflection on the difference of wall-tangent velocity as affected by the hub and shroud. It is seen that, from $S / S_{0}=0.6-1.0$, the skin friction coefficient on the pressure surface basically remains unchanged. From $S / S_{0}=0.6$ to the outlet of the impeller, the magnitude of skin friction coefficient is relatively smaller close to the shroud, indicating that the velocity gradient of the boundary layer flow gradually decreases from hub to shroud. In terms of suction surface in Figure 14b, it is found that, from $S / S_{0}=0.0-0.1$, the magnitude of skin friction coefficient decreases gradually close to the hub. Meanwhile, the skin friction coefficient begins to rise relatively from $S / S_{0}=0.1-0.4$ close to the shroud, which indicates that the velocity gradient of the boundary layer forms a mechanism called dynamic balance from $S / S_{0}=0.0-0.4$ between hub and shroud. Dynamic balance mechanism could effectively suppress boundary layer separation; thus, the flow in passage II remains relatively smooth, as shown in Figure 4.

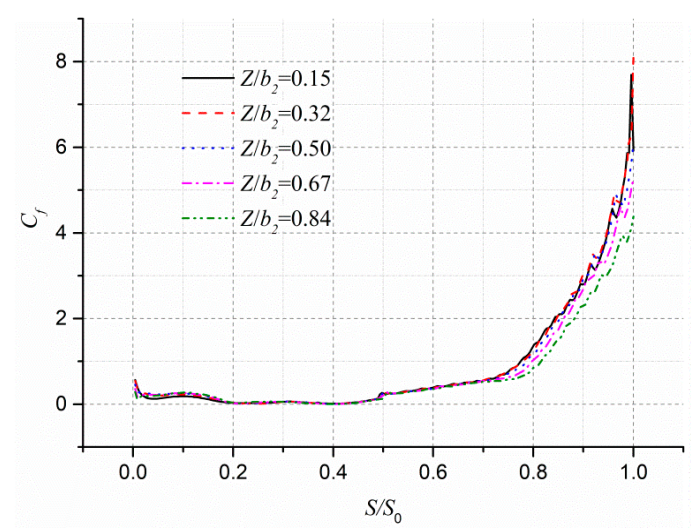

(a)

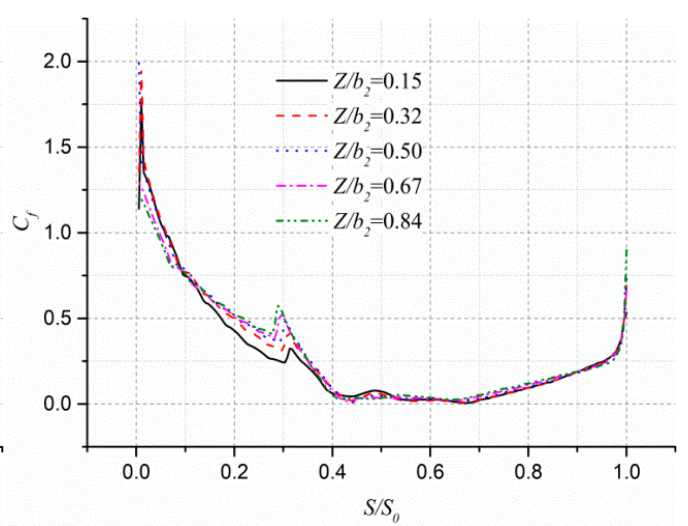

(b)

Figure 14. Comparison of the skin friction coefficient on the blade surface at different axial cross sections: (a) pressure surface and (b) suction surface. 


\subsection{Three-Dimensionality of Main Flow in Stalled and Unstalled Passages}

It is well known that the boundary layer flow is greatly determined by the main flow outside of the boundary layer. In this section, we present and analyze the three-dimensionality of the main flow in the stalled and unstalled passages. The circumferential distribution of normalized radial velocity $\mathrm{U}_{r} / \mathrm{U}_{1}$ on different radial positions of the $Z / b_{2}=0.50$ cross section is given in Figure 14 , in which $\mathrm{U}_{1}$ is the averaged inflow velocity. In the figure, the radial position is represented by the normalized value $r^{*}=\left(r-r_{1}\right) /\left(r_{2}-r_{1}\right)$, where $r_{1}$ and $r_{2}$ are the radii of the inlet and outlet of the blade, and ps1/ss1 and ps2/ss2 represent the pressure/suction surfaces of the stalled and unstalled passages, respectively. Since the separation of boundary layer flow results in large-scale vortices, the flow in the unstalled passage II will not be greatly affected by the main flow while the flow in the stalled passage I will be significantly influenced.

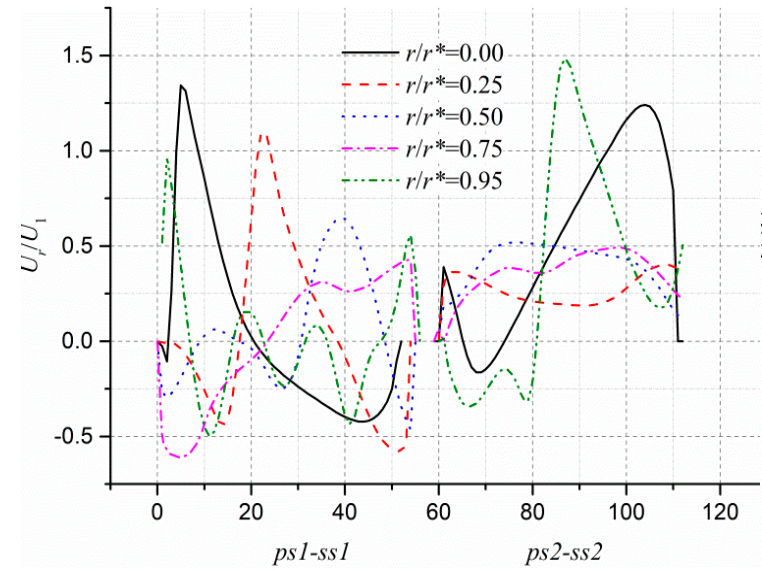

(a)

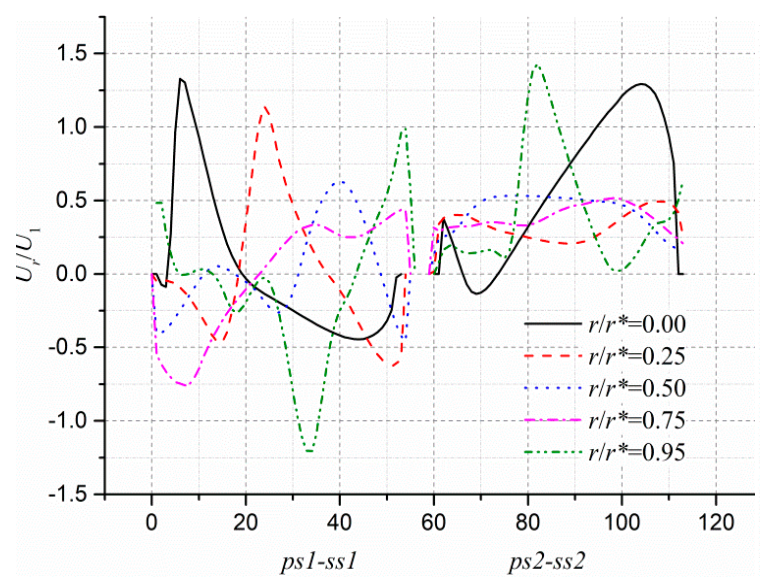

(b)

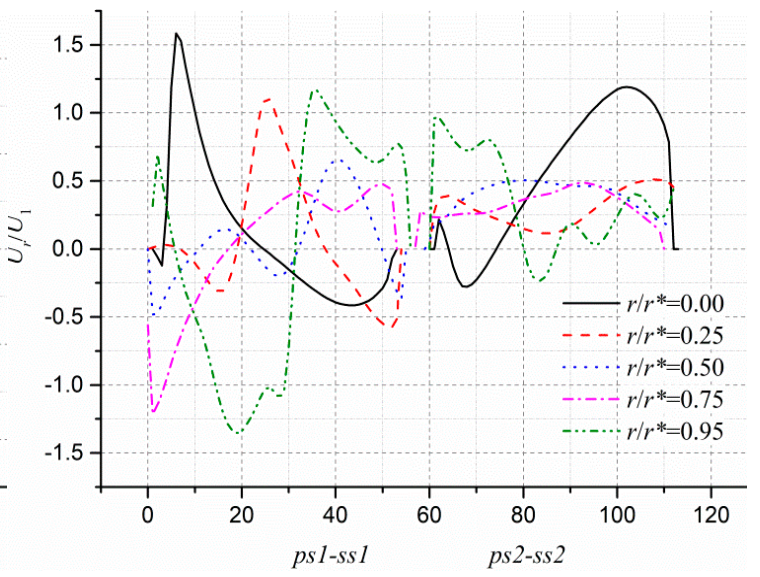

(d)

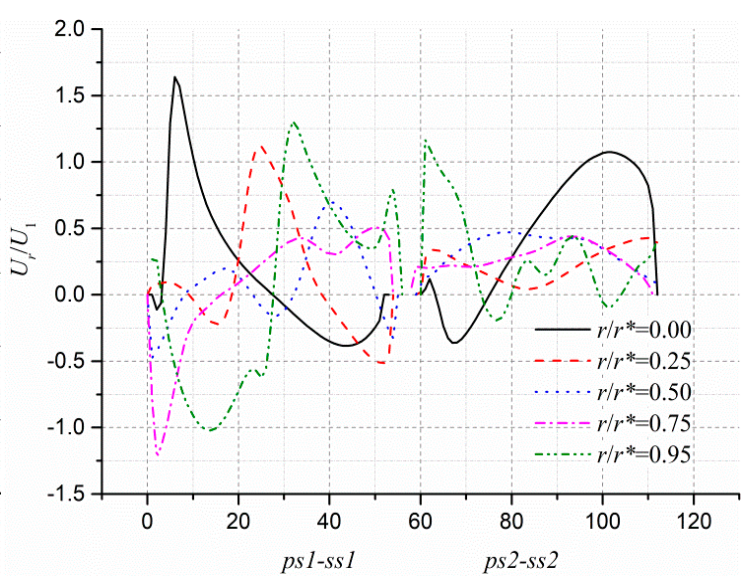

(e) 


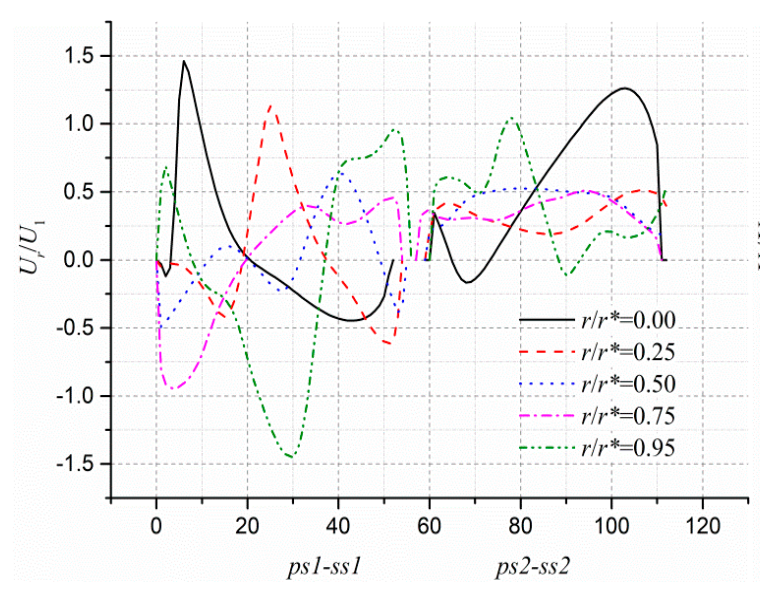

(c)

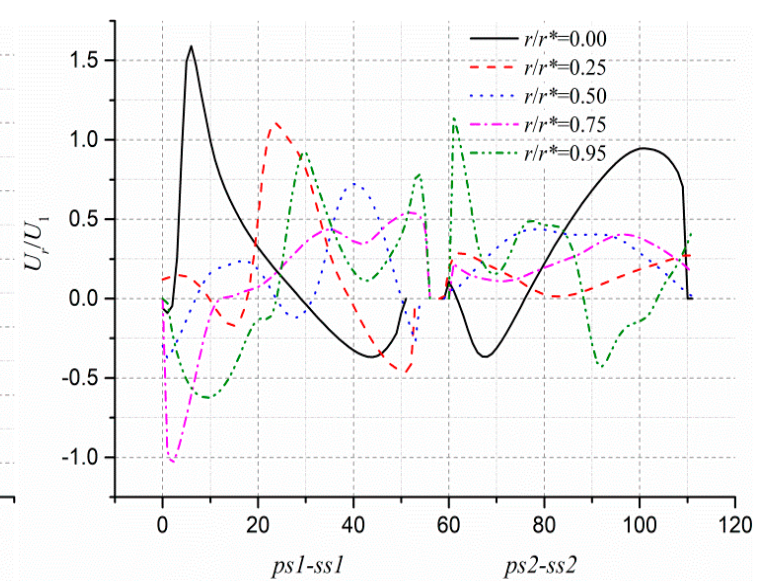

(f)

Figure 14. Blade-to-blade distribution of instantaneous radial velocity for the $Z / b_{2}=0.5$ cross section: (a) $t=1 / 12 T$, (b) $t=3 / 12 T$, (c) $t=5 / 12 T$, (d) $t=7 / 12 T$, (e) $t=9 / 12 T$, and (f) $t=11 / 12 T$.

In Figure $14 a$, at the inlet of the impeller $r^{*}=0.00$, the flow in passage II exhibits the same primary characteristics as the flow at a designed flow rate [4], with the addition of weak reversed flow near the pressure surface. The reversed flow on the pressure side is weak, and the flow is relatively stable from $r^{*}=0.00$ to $r^{*}=0.75$. At the radial position $r^{*}=0.95$ close to the outlet of the impeller, the radial velocity on the pressure side of passage I presents a fluctuating state under the influence of wake flow, and the flow is very unstable. Also, at the radial position $r^{*}=0.00$, the forward flow in passage I covers one-third of the passage, the reversed flow covers the remaining two-thirds, and the maximum reversal velocity reaches $31 \%$ of the maximum magnitude. At the position $r^{*}=0.25$, the positive peak velocity exists in the center of the passage, providing energy for recirculation of the separated vortex. At $r^{*}=0.50$, the peak velocity moves to the suction surface due to enhancement of the vortices, and the velocity is reduced to 0.52 . At the outer radial position $r^{*}=0.95$, the area covered by the forward flow of passage I is less than one-third of the flow passage, indicating that the large area of separated vortex near the outlet results in the lowest capacity of through-flow. In the other subfigures, the flow development trends at different radial positions are very similar.

\section{Conclusions}

This work performs a numerical investigation on the evolution behaviors of separated vortices and near-wall flow in a centrifugal impeller operated in off-designed flow rate condition. The flow characteristics are simulated using the URANS approach, which is well validated, and are discussed and analyzed in terms of temporal variations and three-dimensionality characteristics of flow in the stalled and unstalled passages of the impeller. The following conclusions are obtained:

(1) At the axial cross section $Z / b_{2}=0.15$, the APG of the pressure surface of the stalled passage at the beginning of the blade generally shows a sharp increase, while the magnitude of APG on the suction surface shows a slight increase within a vortex formation period. At $S / S_{0}=0.4$, the wall shear stress of the blade pressure surface also increases sharply, and the peak value reaches about 2.0. The wall shear stress of the suction surface of the blade slowly increases, and the peak value reaches about 7.5 at the impeller outlet section. The large-scale vortex is seen almost blocking the flow channel which decays, merges, sheds, and grows in time.

(2) At the axial cross section $Z / b_{2}=0.5$, the AFG of the pressure surface and suction surface of the stalled passage are similar to the variation at $Z / b_{2}=0.15$. However, the wall shear stress of the pressure surface increases rapidly at first and then slowly increases near $S / S_{0}=0.4$. The peak value 
of wall shear stress reaches about 4.0. Although the variation trend of the wall shear stress of the suction surface also exhibits peaks and valleys, the peak value reaches about 0.8 . Comparing the wall shear stress of the same pressure surface at different axial positions, it is found that the wall shear stress increases the most at the beginning of $S / S_{0}=0.6$.

(3) At the axial cross section $Z / b_{2}=0.15$, the APG of the pressure surface of the unstalled passage is at around the inlet of the impeller $\left(S / S_{0}=0.4\right)$, in which FPG generally shows a decreasing trend, while the FPG of the suction surface shows a slow decrease. The wall shear stress of the pressure surface shows an increasing trend near $S / S_{0}=0.5$, and its peak value reaches about 7.5. A large-scale vortex can be seen at the impeller outlet. At the entrance of the impeller, the wall shear stress of the suction surface varies from 1.5 to 1.7. The velocity gradient is hardly disturbed; thus, the near-wall flow of the suction surface is relative stable.

(4) At the axial cross-section $Z / b_{2}=0.5$, the FPG of the pressure and suction surfaces of the unstalled passage show similar distributions. The wall shear stress of the pressure surface is approximately the same as that of $Z / b_{2}=0.15$. At the entrance of the impeller, the wall shear stress of the suction surface varies from 1.5 to 2.0, which is slightly higher. Although the peak value has increased by about 0.2 , the flow in the vicinity of the suction surface is relatively stable.

(5) From the inlet to outlet of the stalled passage, the peak positive value of radial velocity gradually approaches the suction side, and the reversed flow zone gradually expands, indicating that a large area of the vortex appears in the outlet area and deteriorates the through-flow capacity of the passage.

The findings obtained by this work reflect the essential three-dimensional characteristics of the internal flow in a centrifugal impeller. Referring to the conclusions, the engineering design and optimization of such a type of impeller should take into consideration the different flow patterns from the shroud to hub sections to avoid possible flow separation that deteriorates the performances. Further studies considering the interactions of flow in the impeller and volute are necessary for the realistic centrifugal pump or fan systems.

Author Contributions: Conceptualization, W.Z.; data curation, S.Z.; formal analysis, S.Z., P.L., and W.Z.; funding acquisition, P.L., W.Z., and Z.Z.; investigation, S.Z.; methodology, S.Z.; project administration, P.L. and W.Z.; resources, P.L. and W.Z.; software, S.Z.; supervision, P.L. and W.Z.; validation, S.Z.; visualization, S.Z.; writing-original draft, S.Z.; and writing-review and editing, P.L. and W.Z. All authors have read and agreed to the published version of the manuscript.

Funding: This work was supported by the National Natural Science Foundation of China (51706205 and 51676173).

Conflicts of Interest: The authors declare no conflict of interest.

\section{References}

1. Xia, X.J.; Deng, X.Y. Engineering Separation Dynamics, 1st ed.; Beihang University Press: Beijing, China, 1991; pp. 233-235.

2. Zhou, P.J.; Dai, J.C.; Li, Y.F. Unsteady flow structures in centrifugal pump under two types of stall conditions. J. Hydrodyn. 2018, 30, 1038-1044. [CrossRef]

3. Andreas, L.; Gunther, B. Numerical simulation and evaluation of velocity Fluctuations during rotating stall of a centrifugal pump. J. Fluids Eng. 2011, 133, 081102.

4. Byskov, R.K.; Jacobsen, C.B.; Pedersen, N. Flow in a centrifugal pump impeller at design and off-design conditions-Part I: Particle image velocimetry(PIV) and laser Doppler velocimery(LDV) measurements. J. Fluids Eng. 2003, 125, 61-72. [CrossRef]

5. Tan, L.; Zhu, B.S.; Cao, S.L. Numerical simulation of unsteady cavitation flow in a centrifugal pump at off-design conditions. Proc. Inst. Mech. Eng. Part C J. Eng. Mech. 2014, 228, 1994-2006.

6. Olivier, P.; Hakan, N. Numerical investigations of unsteady flow in a centrifugal pump with a vaned diffuser. Int. J. Rotating Mach. 2013, 2013, 961580.

7. Huang, X.B.; Liu, Z.Q.; Li, Y.J. Study of the internal characteristics of the stall in a centrifugal pump with a cubic non-linear SGS model. J. Hydrodyn. 2019, 31, 788-799. [CrossRef] 
8. Ren, X.M.; Fan, H.G.; Xie, Z.F. Stationary stall phenomenon and pressure fluctuation in a centrifugal pump at partial load condition. Heat Mass Transf. 2019, 55, 2277-2288. [CrossRef]

9. Akiha, S.; Hideto, H.; Shutaro, K. Study of flow instability in off design operation of a multistage centrifugal pump. J. Mech. Sci. Technol. 2016, 30, 493-498.

10. Manish, S.; Ali, P.; Joseph, K. The flow structure during onset and developed states of rotating stall with a vaned diffuser of a centrifugal pump. J. Fluids Eng. 2001, 123, 490-499.

11. Akin, O.; Rokwell, D. Interaction of zones of flow separation in a centrifugal impeller-stationary vane system. Exp. Fluids 1994, 17, 427-433. [CrossRef]

12. Elias, S.; Bernhard, S.; Mihai, M. Generation mechanisms of rotating stall and surge in centrifugal compressors. Flow Turbul. Combust. 2018, 100, 705-719.

13. Taher, H.; Mohamed, A.; Mohamed, S.G. Numerical investigation of rotating stall in compressor with vaned and vaneless diffuser. J. Therm. Sci. 2015, 24, 323-333.

14. Zhang, L.; He, R.Y.; Wang, S.L.; Zhang, Q. A review of rotating stall in vaneless diffuser of centrifugal compressor. J. Therm. Sci. 2020, 29, 323-342. [CrossRef]

15. Nobumichi, F.; Shotaro, H.; Yutaka, O. Unsteady behavior of leading-edge vortex and diffuser stall in a centrifugal compressor with vaned diffuser. J. Therm. Sci. 2016, 25, 13-21.

16. Dazin, A.; Coutier-Delgosha, O.; Dupont, P. Rotating instability in the vaneless diffuser of a radial flow pump. J. Thermal Sci. 2008, 17, 368-374. [CrossRef]

17. Feng, J.; Benra, F.; Dohmen, H.J. Unsteady flow visualization at part load conditions of a radial diffuser pump: By PIV and CFD. J. Vis. 2009, 12, 65-72. [CrossRef]

18. Krause, N.; Zähhringer, K.; Pap, E. Time-solved particle imaging velocimetry for the investigation of rotating stall in a radial pump. Exp. Fluids. 2005, 39, 192-201. [CrossRef]

19. Li, W.; Li, E.D.; Ji, L.L.; Zhou, L.; Shi, W.; Zhu, Y. Mechanism and propagation characteristics of rotating stall in a mixed flow pump. Renew. Energy 2020, 153, 74-92. [CrossRef]

20. Kan, K.; Zheng, Y.; Chen, Y.J.; Xie, Z.S.; Yang, G.; Yang, C. Numerical study on the internal flow characteristics. J. Mech. Sci. Technol. 2018, 32, 4683-4695. [CrossRef]

21. Zhang, H.; Yang, C.; Yang, D.; Wang, W.; Yang, C.; Qi, M. Investigation on the Stall Inception Circumferential Position and Stall Process Behavior in a Centrifugal Compressor with Volute. In Proceedings of the ASME Turbo Expo 2018: Turbomachinery Technical Conference \& Exposition, Oslo, Norway, 11-15 June 2018; ASME: New York, NY, USA, 2018.

22. Ceyrowsky, T.; Hildebrandt, A.; Schwarze, R. Numerical investigation of the circumferential pressure distortion induced by a centrifugal compressor's external volute. In Proceedings of the ASME Turbo Expo 2018: Turbomachinery Technical Conference \& Exposition, Oslo, Norway, 11-15 June 2018; ASME: New York NY, USA, 2018.

23. Cravero, C.; Marsano, D. Criteria for the stability limit prediction of high-speed centrifugal compressors with vaneless diffuser. Part I: Flow structure analysis. In Proceedings of the ASME Turbo Expo 2020: Turbomachinery Technical Conference and Exposition, Virtual Conference, London, UK, 21-25 September 2020; ASME: New York, NY, USA, 2020.

24. Cravero, C.; Marsano, D. Criteria for the stability limit prediction of high-speed centrifugal compressors with vaneless diffuser. Part II: The development of prediction criteria. In Proceedings of the ASME Turbo Expo 2020: Turbomachinery Technical Conference and Exposition, Virtual Conference, London, UK, 21-25 September 2020; ASME: New York, NY, USA, 2020.

25. Fu, S.; Launder, B.E.; Leschziner, M.A. Modeling strongly swirling recirculating jet flow with Reynolds-stress transport closures. In Proceedings of the 6th Symposium on Turbulent Shear Flows, Toulouse, France, 7-9 September 1987; Springer: Berlin, Germany, 1987.

Publisher's Note: MDPI stays neutral with regard to jurisdictional claims in published maps and institutional affiliations. 